\title{
Chlorendic Acid
}

National Cancer Institute

\section{Source}

National Cancer Institute. Chlorendic Acid. NCI Thesaurus. Code C44353.

A white, crystalline carcinogenic chlorinated hydrocarbon that emits toxic fumes of hydrochloric acid and other chlorinated compounds when heated to decomposition. Chlorendic acid is used as a reactive flame retardant, chemical intermediate, hardening agent and as an extreme pressure lubricant. Exposure to chlorendic acid causes skin, eye and respiratory tract irritation. Chlorendic acid is reasonably anticipated to be a human carcinogen based on evidence of carcinogenicity in experimental animals. ( $\mathrm{NCl05)}$ 